\title{
THE OPTIMUM GROWTH RATE FOR POPULATION RECONSIDERED
}

Klaus Jaeger and Wolfgang Kuhle 


\section{The Optimum Growth Rate for Population}

\section{Reconsidered}

K. Jaeger ${ }^{1}$ and W. Kuhle ${ }^{2}$

Abstract. This article gives exact general conditions for the existence of an interior optimum growth rate for population in the neoclassical two-generations-overlapping model. In an economy where high (low) growth rates of population lead to a growth path which is efficient (inefficient) there always exists an interior optimum growth rate for population. In all other cases there exists no interior optimum. The Serendipity Theorem, however, does in general not hold in an economy with government debt. Moreover, the growth rate for population which leads an economy with debt to a golden rule allocation can never be optimal.

Key words: Optimal population, Serendipity Theorem, Debt, Social Security, Overlapping Generations

\section{Introduction}

It was Phelps (1967) who brought up the idea that there might exist a "golden rule of procreation" in the neoclassical overlapping generations framework. In a subsequent article on "the optimum growth rate for population" Samuelson (1975a) proved - within the basic Diamond (1965) model without government debt - the so-called Serendipity Theorem: provided that there exists only one stable steady state equilibrium, the competitive economy will automatically evolve into the most golden golden rule steady state once the optimum growth rate for population $n^{*}$ is imposed.

However, Deardorff (1976) pointed out that the optimum growth rate for population $n^{*}$ of Samuelson (1975a) is not optimal in general. In the special case where both the utility and the production function are of the Cobb-Douglas type utility takes on a global minimum at the $n^{*}$ of Samuelson. Deardorff also proved that there always exists an optimal corner solution where $n^{*}=-\delta$ as long as the elasticity of substitution between

\footnotetext{
${ }^{1}$ Department of Economics, Free University of Berlin, Boltzmannstr. 20, 14195 Berlin; e-mail: jaegerkl@zedat.fu-berlin.de

${ }^{2}$ Department of Economics, University of Mannheim, MEA Mannheim, L 13, 68131 Mannheim; e-mail: kuhle@mea.uni-mannheim.de
} 
capital and labor remains bound above unity. This discussion has been supplemented by Michel and Pestieau (1993), who treat the special case of a CES/CIES framework.

After all, the debate can be summarized as follows: granted that the respective elasticities of substitution (in consumption and more importantly production) are not "too large" there does exist an interior optimum growth rate for population $n^{*}>-\delta$ in the planned economy. The greatest deficiency in this discussion appears to be the fact that it was necessary to resort to a multitude of special cases in order to examine the significance of the Serendipity Theorem. Especially since Samuelson (1976) points out, that the respective elasticities of substitution are hard to estimate and are prone to change once the growth rate for population is altered.

\section{Method and Principal Results}

The intention with this essay is twofold:

1. In a first step we will, contrary to the foregoing essays, use a laissez faire framework to derive exact general sufficient conditions for the existence of an interior optimum growth rate for population in the Diamond (1965) model without government debt.

2. In a second step we will reconsider the validity of the results of Samuelson (1975a) in the general Diamond (1965) model with government debt.

With respect to the first point we will proceed along the following lines: our theoretical starting point will be the planning problem of Samuelson (1975a) where an imaginary authority can set all quantities to their respective optimal level. In a second step we will discuss a laissez faire framework where the imaginary authority can only vary the growth rate for population. In this competitive framework we will use the stability condition to derive a $r-n$ relation. This crucial $r-n$ relation will then allow to draw the following conclusions:

1. The necessary and sufficient conditions for the existence of an interior optimum growth rate for population in a planned economy and in a laissez faire economy are identical.

2. The existence of an interior optimum growth rate for population hinges solely on the change in efficiency, which occurs in the laissez faire economy once the growth 
rate for population is changed (increased or decreased) from the optimal/worst level, where $n=n^{*}=r$. Along these lines we find that it is necessary to distinguish four cases in order to give a complete assessment of the problem of optimal population. Only one of these four cases has been treated by Samuelson (1975a).

3. The exact sufficient condition for the existence of an optimum growth rate for population is given by $\left.\frac{d r}{d n}\right|_{n=n^{*}}>1$.

As previously mentioned, we will then generalize the foregoing discussion by introducing government debt into the framework of analysis. In such a framework we find that:

1. The Serendipity Theorem does not hold in an economy with government debt.

2. In an economy with debt there typically still exists a growth rate $\tilde{n} \gtrless n^{*}$ for population which leads the laissez faire economy to a golden rule allocation. However, this growth rate will never be optimal. Instead, the optimum growth rate for population $n^{* *}$ in a laissez faire economy with government debt will lead to an allocation where $r>n$.

\section{The Optimum Growth Rate for Population with- out Debt}

\subsection{The Planning Problem}

The planning problem in the conventional Diamond (1965) model, for given growth rates of population, can be stated as: ${ }^{3}$

$$
\max _{c^{1}, c^{2}, k} U\left(c^{1}, c^{2}\right) \quad \text { s.t. } \quad f(k)-n k=c^{1}+\frac{c^{2}}{(1+n)} ; \quad f^{\prime}(k)>0, \quad f^{\prime \prime}(k)<0 .
$$

With the familiar first order conditions:

$$
\begin{aligned}
\frac{U_{c^{1}}}{U_{c^{2}}} & =1+n, \\
f^{\prime}(k) & =n, \\
f(k)-n k & =c^{1}+\frac{c^{2}}{(1+n)} .
\end{aligned}
$$

\footnotetext{
${ }^{3}$ Population grows according to: $N_{t}=(1+n) N_{t-1}$. The availability constraint for the economy is given by: $F\left(K_{t}, N_{t}\right)+K_{t}=K_{t+1}+c_{t}^{1} N_{t}+c_{t}^{2} N_{t-1}$. In the following we compare different steady state equilibria and hence the time index will be omitted where no misunderstanding is expected.
} 
Condition (2) describes the optimal distribution of income between the generations. Condition (3) describes the optimal accumulation pattern. Taken together conditions (2) and (3) constitute the two-part golden rule. Condition (4) is the social availability/budget constraint. These three conditions define (truly) optimal values $c_{n}^{1}, c_{n}^{2}$ and $k_{n}$ for every given growth rate of population.

By varying the growth rate for population, as in Samuelson (1975a), it is now possible to choose the best among all golden rule paths, i.e. the optimum optimorum:

$$
\max _{n} U(n)=U\left(f\left(k_{n}\right)-n k_{n}-\frac{c_{n}^{2}}{(1+n)}, c_{n}^{2}\right),
$$

where $U(n)$ is the indirect utility function for the planned economy. The first order condition to this problem is:

$$
-k_{n}+\frac{c_{n}^{2}}{(1+n)^{2}}=0
$$

The corresponding sufficient condition is given by:

$$
{\frac{d^{2} U}{d n^{2}}}_{\mid n=n^{*}}=U_{c^{1}}\left(-\frac{d k_{n}}{d n}+\frac{(1+n)^{2} \frac{d c_{n}^{2}}{d n}-2(1+n) c_{n}^{2}}{(1+n)^{4}}\right)<0 .
$$

Condition (6) describes the tradeoff between the negative capital widening $\left(-k_{n}\right)$ and the positive intergenerational transfer $\left(\frac{c_{n}^{2}}{(1+n)^{2}}\right)$ effect, and implicitly defines the optimum growth rate for population.

Together conditions (2)-(4) and (6) implicitly define optimal values $c^{1 *}, c^{2 *}, k^{*}, n^{*}$ which characterize the social optimum optimorum. ${ }^{4}$ However, as previously noted, the first order condition (6) might locate the growth rate for population where the indirect utility function $U(n)$ takes on a global minimum rather than a maximum, i.e. we might

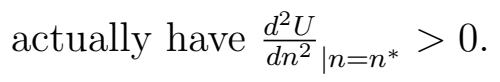

The Serendipity Theorem: The representative individual is driven by the following maximization problem:

$$
\max _{c^{1}, c^{2}} U\left(c^{1}, c^{2}\right) \quad \text { s.t. } \quad w=c^{1}+\frac{c^{2}}{(1+r)} ; \quad w=f(k)-f^{\prime}(k) k, \quad r=f^{\prime}(k) .
$$

With the corresponding first order conditions:

$$
\begin{aligned}
\frac{U_{c^{1}}}{U_{c^{2}}} & =1+r \\
f(k)-r k & =c^{1}+\frac{c^{2}}{(1+r)} .
\end{aligned}
$$

\footnotetext{
${ }^{4}$ In the following we will assume that there is only one unique solution to the first order conditions (2)-(4) and (6).
} 
Once we set $k=k^{*}$ and $n=n^{*}$ so that conditions (3) and (6) hold, we find that the individual behavior, which is described by conditions (9) and (10), is compatible with the remaining conditions (2) and (4) for the social optimum. Since condition (6), with $r=n^{*}$, is identical with the steady state life-cycle savings condition, we find that the values $c^{1 *}, c^{2 *}, k^{*}, n^{*}$ describe a feasible laissez faire steady state equilibrium. This is the Serendipity Theorem of Samuelson (1975a): provided that there exists only one stable steady state equilibrium, the competitive economy will automatically evolve into the most golden golden rule steady state once the optimum growth rate $n^{*}$ is imposed.

\subsection{The Optimum Growth Rate for Population in a Laissez Faire Economy}

In order to analyze the welfare implications of changes in the growth rate for population in the laissez faire economy we will assume that consumption in each period is a normal good, and use the life-cycle savings condition which is given by:

$$
(1+n) k_{t+1}=s\left(w_{t}, r_{t+1}\right) ; \quad 0<s_{w}<1
$$

Furthermore, we assume the existence of one unique and stable steady state equilibrium with a capital intensity $k=\tilde{k}>0$ :

$$
0<\frac{d k_{t+1}}{d k_{t}}=\frac{-s_{w} \tilde{k} f^{\prime \prime}(\tilde{k})}{(1+n)-s_{r} f^{\prime \prime}(\tilde{k})}<1 .
$$

Differentiation of (11) allows, by virtue of (12), to derive that an increase in the growth rate for population decreases the steady state capital intensity:

$$
\frac{d k}{d n}=\frac{-k}{(1+n)-s_{r} f^{\prime \prime}(k)+s_{w} k f^{\prime \prime}(k)}<0 .
$$

From the life-cycle savings condition (11), the respective factor-prices, and the individual budget constraint, one obtains the following maximization problem for the laissez-faire economy:

$$
\max _{n} U(n)=U\left(f(k)-f^{\prime}(k) k-(1+n) k,\left(1+f^{\prime}(k)\right)(1+n) k\right) ; \quad k=k(n) .
$$

Condition (9), which is always satisfied in a laissez faire economy, allows to rewrite the first order condition for the optimum growth rate for population so that we have:

$$
\frac{d U}{d n}=U_{c^{1}}\left[\frac{n-f^{\prime}(k)}{1+f^{\prime}(k)} f^{\prime \prime}(k) k\right] \frac{d k}{d n}=0 .
$$


According to the Serendipity Theorem, condition (15) holds only for $n=n^{*}$. The sufficient condition for an optimum at $n^{*}$ is given by:

$$
\frac{d^{2} U}{d n^{2}}{ }_{\mid n=n^{*}}=U_{c^{1}}\left[\frac{\left(1-f^{\prime \prime}(k) \frac{d k}{d n}\right)}{\left(1+f^{\prime}(k)\right)} f^{\prime \prime}(k) k\right] \frac{d k}{d n}<0 .
$$

Condition (16) reveals that the existence of an optimum or a minimum or an inflection point at $n^{*}$ hinges solely on:

$$
\frac{d r}{d n}_{\mid n=n^{*}}=f^{\prime \prime}(k) \frac{d k}{d n}=\frac{-k}{\frac{1}{f^{\prime \prime}}(1+n)+s_{w} k-s_{r}} \gtreqless 1 .
$$

However, a priori we can only say that $\frac{d r}{d n}>0$, if the steady state equilibrium is stable. Hence it is necessary to distinguish four cases:

Case 1: The economy is growing on a dynamically inefficient (efficient) steady state path where $r<n(r>n)$ for low (high) growth rates of population $n<n^{*}\left(n>n^{*}\right)$. In this case we have $\left.\frac{d r}{d n}\right|_{n=n^{*}}>1$, and the sufficient condition for an interior maximum is satisfied.

Case 2: The economy is growing on an efficient (inefficient) steady state path for low (high) growth rates $n<n^{*}\left(n>n^{*}\right)$. In this case we have $\left.\frac{d r}{d n}\right|_{n=n^{*}}<1$, that is, an interior minimum.

Case 3: The economy is growing on an inefficient path for all $n \neq n^{*}$. In this case we have $\left.\frac{d r}{d n}\right|_{n=n^{*}}=1$ and population should grow as fast as possible. There is an inflection point in the $U(n)$ curve at $n=n^{*}$.

Case 4: All steady states are efficient and the lowest possible growth rate for population is best. We have, once again, an inflection point in the $U(n)$ curve at $n=n^{*}$ and $\frac{d r}{d n}_{n=n^{*}}=1$.

After these preparations it is now possible to give a complete diagrammatic representation of the problem of optimal population in Diagram 1 (the formal aspects to Diagram 1 are given in Appendix A): 


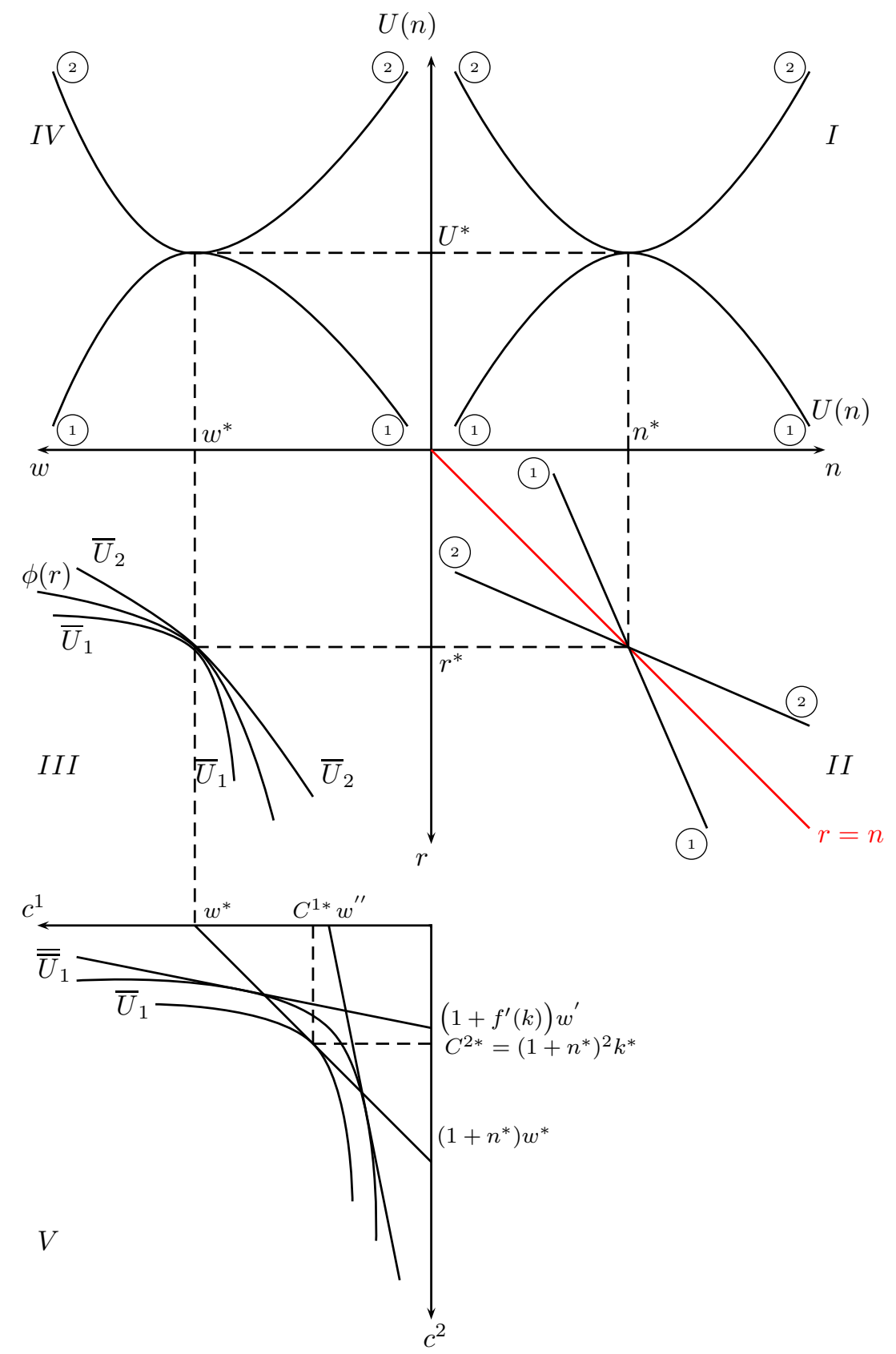

Diagram 1: Quadrant I is the familiar $U, n$ diagram which contains the respective utility contours for the laissez faire economy. Quadrant II is the decisive $n, r$ diagram where all planned equilibria are located along the $45^{\circ}$ line. The locus of the laissez faire steady state curve with $\frac{d r}{d n}=f^{\prime \prime}(k) \frac{d k}{d n}>0$ is ambiguous and four cases have to be distinguished: Case 1: 1-1, Case 2: 2-2, Case 3: 1-2, Case 4: 2-1. Quadrant III is a $w, r$ diagram which contains the convex factor price frontier $\phi$ and the respective indifference curves indicating an optimum (pessimum). Quadrant IV gives the wage utility relation. Quadrant $V$ illustrates the respective individual consumption patterns for different growth rates (Case 1 only). 
At this point we can note that the factor prices which are associated with the twopart golden rule allocation - for all given growth rates $n \neq n^{*}-$ allow in general to reach a higher indifference curve in Quadrant III than the set of factor prices which is generated in the laissez faire framework.

More interesting, however, is a related point which can be found in Quadrant III of Diagram 1: the conditions for the existence of an interior optimum growth rate $n^{*}$ in a planned economy, where the central authority forces $r=n$ as in Samuelson (1975b), are identical with those in a laissez faire economy: in both cases it is necessary that the indifference curve in the $w, r$ plane is a tangent to the factor price frontier, i.e. $\left.\frac{d w}{d r}\right|_{d U=0}=\phi^{\prime}(r)$, and it is sufficient that the curvature of the indifference curve is algebraically larger than the curvature of the factor price frontier, i.e. $\frac{d^{2} w}{d r^{2}} \mid d U=0>\phi^{\prime \prime}(r)$.

This means that regardless of whether we are in a planned economy or a laissez faire economy: choosing the growth rate for population means choosing a set of factor-prices on the same factor-price frontier. The convex factor-price frontier, which in general defines a concave set of feasible allocations, should be interpreted as a surrogate social budget constraint.

Proposition 1: The necessary and sufficient conditions for the existence of an interior optimum growth rate for population in a planned and in a laissez faire economy are identical. The exact general sufficient condition for an interior optimum growth rate for population is given by $\left.\frac{d r}{d n}\right|_{n=n^{*}}>1$. In all other cases where the structure of the economy is such that we have $\left.\frac{d r}{d n}\right|_{n=n^{*}} \leqq 1$ in the laissez faire framework there does not exist an interior optimum.

We prove Proposition 1 in Appendix B. Thus the qualitative findings of Michel and Pestieau (1993) for the planning problem in a CES/CIES economy remain fully valid for a laissez faire economy. All specifications, most notably the Cobb-Douglas case, where there is an interior planned minimum are consistent with Case 2 and the counterintuitive change in efficiency at $n=n^{*}$. In our opinion it is this dubious behavior of economies with high elasticities of substitution that should be criticized and not the behavior in the two "corners" where $k \rightarrow \infty$ or $n \rightarrow \infty$ as in Samuelson (1976). ${ }^{5}$

\footnotetext{
${ }^{5}$ At this point we shall note that Phelps (1968) shows for a laissez faire economy that the CobbDouglas case is consistent with what we have called Case 2, i.e. an interior minimum at $n=n^{*}$. Hence, in the light of the Serendipity Theorem, it should have been no surprise to Deardorff (1976) and Samuelson (1975a) that the "most golden golden rule steady state" must be a minimum in the Cobb-Douglas case.
} 
We can now conclude that the reasoning of Samuelson (1975a) and Samuelson (1975b) only remains valid as long as the economy behaves according to Case 1 . However, the assertion of Samuelson (1975a), (p. 535) and Samuelson (1975b), (p. 542) which was never questioned by Deardorff (1976) or Michel and Pestieau (1993) - that all economies behave according to Case 1 is wrong.

However, Case 1 is obviously the most plausible scenario and the data in Marquetti (2004) for the years 1963-2000 clearly suggest that real world economies behave according to Case 1. Estimates of the $r-n$ relation for Japan, the USA and a group of 17 mostly developed countries allow to refute the null hypothesis $\frac{d r}{d n}<1$ with a probability of error of less than 2,5 percent.

\section{The Optimum Growth Rate for Population in an Economy with Government Debt}

We will now proceed along the following lines: in a first step the Diamond (1965) model with internal government debt and the corresponding government budget constraint will be restated. In a second step we will show that the Serendipity Theorem is in general not valid in an economy with government debt. The third step is to derive the welfare implications which stem from a change in the growth rate of population in a laissez faire economy where the government runs a constant per capita debt policy.

The Model: The Diamond (1965) model with debt differs from the one which was discussed in the foregoing section only with respect to the government budget constraint and the steady state life-cycle savings condition.

The Government Budget Constraint: Government debt has a one-period maturity and yields the same interest as real capital and there is no risk of default. In each period the government has to service the matured debt $B_{t-1}$, and it has to pay interest amounting to $f^{\prime}\left(k_{t}\right) B_{t-1}$. The government can use two tools to meet these obligations: it can raise a lump-sum tax $N_{t} \tau_{t}^{1}$ from the young generation, or it can issue new debt $B_{t}$. Hence we have:

$$
B_{t}+N_{t} \tau_{t}^{1}=\left(1+f^{\prime}\left(k_{t}\right)\right) B_{t-1}
$$

In the following the government will simply pursue a constant per capita debt policy (Persson and Tabellini (2000) give reasons why an elected government might rather run such a debt policy than use its budget constraint to steer the economy towards the long 
run optimum) defined by:

$$
\frac{B_{t-1}}{N_{t}}=b \quad \forall t
$$

Thus (18) simplifies to:

$$
\tau^{1}=\left[\left(1+f^{\prime}\left(k_{t}\right)\right)-(1+n)\right] b=\left(f^{\prime}\left(k_{t}\right)-n\right) b=\tau^{1}\left(k_{t}\right) .
$$

Equation (20) reveals that taxes can be either positive or negative depending on $b \gtrless 0$ and the sign of $\left(f^{\prime}(k)-n\right)$, i.e. on whether the economy is growing on an efficient or inefficient path.

\subsection{The Serendipity Theorem with Debt}

From the perspective of the social planner the problem remains unaltered: the relevant tradeoff is still between capital widening and the intergenerational transfer effect, and conditions (2)-(4) and (6) still describe the social optimum.

The Competitive Economy with Government Debt: The individual utility maximization problem is given by:

$$
\max _{c^{1}, c^{2}} U\left(c_{t}^{1}, c_{t+1}^{2}\right) \quad \text { s.t. } \quad w\left(k_{t}\right)-\tau_{t}^{1}\left(k_{t}\right)=c_{t}^{1}+s_{t} ; \quad c_{t+1}^{2}=\left(1+f^{\prime}\left(k_{t+1}\right)\right) s_{t} .
$$

Thus the representative individual behaves according to:

$$
\begin{aligned}
\frac{U_{c^{1}}}{U_{c^{2}}} & =1+f^{\prime}\left(k_{t+1}\right), \\
s_{t} & =w\left(k_{t}\right)-\tau_{t}^{1}\left(k_{t}\right)-c_{t}^{1}, \\
c_{t+1}^{2} & =\left(1+f^{\prime}\left(k_{t+1}\right)\right) s_{t} .
\end{aligned}
$$

Attainability of the Social Optimum: In a steady state equilibrium the life-cycle savings condition is given by:

$$
s\left(\tilde{w}(k), f^{\prime}(k)\right)=(1+n)(b+k) ; \quad s=(1+n)(b+k)>0 ; \tilde{w}(k):=w(k)-\tau^{1}(k),(25
$$

where $s>0$ is an obvious restriction since negative savings would lead to negative old age consumption. We will now examine whether the social optimum $\left(c^{1 *}, c^{2 *}, n^{*}, k^{*}\right)$, which is characterized by (2)-(4) and (6), is a feasible laissez faire steady state equilibrium: once we set $k=k^{*}$ and $n=n^{*}$, conditions (3) and (6) hold. According to (20) we have $\tau^{1}\left(k^{*}\right)=0$ and the individual budget constraint becomes the same as the availability 
constraint. In this case the individual will voluntarily choose $c^{1 *}$ and $c^{2 *}$. The last thing is to check the steady state life-cycle savings condition:

$$
s^{*}=\left(1+n^{*}\right) k^{*}=\frac{c^{2 *}}{\left(1+n^{*}\right)} \neq\left(1+n^{*}\right)\left(k^{*}+b\right) ; \quad \forall b \neq 0 .
$$

This means that since internal debt leads to the substitution of capital with debt (paper) in the portfolio of the representative individual the Serendipity Theorem does not hold. Thus the only way to decentralize the social optimum is to reduce per capita debt to zero.

\subsection{The Optimum Growth Rate for Population in a Laissez Faire Economy with Debt}

Comparison of the social optimum and the individual behavior revealed that the Serendipity Theorem does not hold in the Diamond model with internally held debt. We will now assess the question of optimal population in a competitive economy. Two related points will be discussed:

1. A change in the constant debt policy for a given growth rate for population.

2. A change in the growth rate for population for a given debt policy.

Temporary Equilibrium: As De La Croix and Michel (2002) point out, there are several conditions which have to be met in each period to allow for a meaningful temporary equilibrium:

$$
\begin{array}{r}
s_{t-1}>0, \\
\tilde{w}\left(k_{t}, b\right)=w\left(k_{t}\right)-\tau^{1}\left(k_{t}\right)=w\left(k_{t}\right)-b\left(f^{\prime}\left(k_{t}\right)-n\right)>0, \\
s\left(\tilde{w}\left(k_{t}, b\right), f^{\prime}\left(k_{t+1}\right)\right)=(1+n)\left(k_{t+1}+b\right)>(1+n) b .
\end{array}
$$

While (27) ensures positive consumption of the old generation, $\tilde{w}$ in (28) describes that the income after taxes of the current young individuals must be positive. Condition (29) must hold to allow for a positive capital intensity.

Steady State Equilibrium: In order to carry out the following comparative static (in per capita terms) analysis, it is necessary to determine the signs of $\frac{d k}{d n}$ and $\frac{d k}{d b}$. As in Diamond (1965), we will assume that there exists one unique stable steady state at $k=\tilde{k}$ :

$$
0<\frac{d k_{t+1}}{d k_{t}}=\frac{-s_{\tilde{w}}(\tilde{k}+b) f^{\prime \prime}(\tilde{k})}{(1+n)-s_{r} f^{\prime \prime}(\tilde{k})}<1 ; \quad 0<s_{\tilde{w}}<1 ; \quad \tilde{k}>0
$$


Total differentiation of the life-cycle savings condition (25) with $d b=0$ leads to:

$$
\frac{d k}{d n}_{\mid d b=0}=\frac{k+\left(1-s_{\tilde{w}}\right) b}{s_{r} f^{\prime \prime}-(1+n)-s_{\tilde{w}}(k+b) f^{\prime \prime}}<0 .
$$

The sign in the denominator of the expression (31) is negative by virtue of the stability condition (30). The assumption of normality $\left(0<s_{\tilde{w}}<1\right)$ and conditions (27) and (29) reveal that the sign of the numerator is positive. Total differentiation of (25) with $d n=0$ yields:

$$
\frac{d k}{d b}_{\mid d n=0}=\frac{(1+n)+s_{\tilde{w}}\left(f^{\prime}-n\right)}{s_{r} f^{\prime \prime}-(1+n)-s_{\tilde{w}} f^{\prime \prime}(k+b)}<0 .
$$

With $0<s_{\tilde{w}}<1$, the sign in the numerator of (32) must be positive. The sign of the denominator is negative according to (30).

Once the signs of $\frac{d k}{d n}$ and $\frac{d k}{d b}$ are known to be negative the key elements to our question can be displayed in Diagram 2.

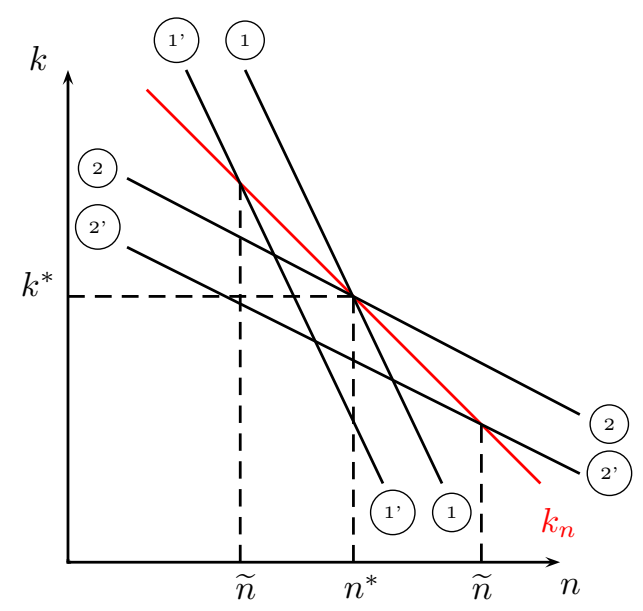

(a)

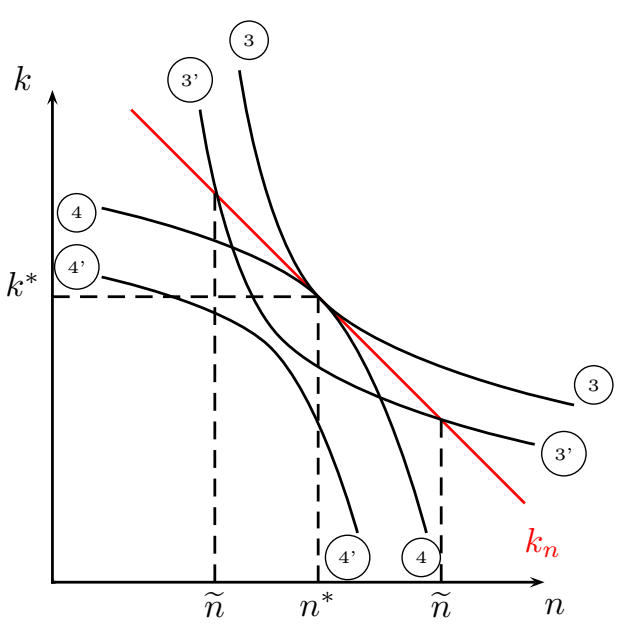

(b)

Diagram 2: The $k_{n}$ line gives the respective golden rule capital intensities and separates the efficient from the inefficient equilibria. For the laissez faire steady state curves, it is once again necessary to distinguish Cases 1, 2, 3 and 4. Once the government issues debt (the debt loci have an apostrophe) these loci shift according to $\frac{d k}{d b}<0$ and the growth rate of population which leads to a golden rule allocation changes from $n^{*}$ to $\tilde{n}$. The Serendipity Theorem does not hold in this case.

Debt and Welfare: After these preparations, the Diamond (1965) result concerning the welfare implications of a change in the constant per capita internal debt policy can be reproduced: from the life-cycle savings condition (25) and the respective factor-prices one obtains the following indirect utility function:

$$
U\left(c^{1}, c^{2}\right)=U\left(f(k)-k f^{\prime}(k)-(1+n)(k+b)-\tau^{1}(k),\left(1+f^{\prime}\right)(1+n)(k+b)\right) .
$$


Using (20) allows to rewrite (33):

$$
U\left(c^{1}, c^{2}\right)=U\left(f(k)-k f^{\prime}(k)-(1+n) k-\left(1+f^{\prime}(k)\right) b,\left(1+f^{\prime}(k)\right)(1+n)(k+b)\right) .
$$

The first order condition for the optimum debt policy is given by:

$$
\frac{d U}{d b}=U_{c^{1}}\left(n-f^{\prime}\right)\left(1+\frac{(k+b)}{\left(1+f^{\prime}\right)} f^{\prime \prime} \frac{d k}{d b}\right) \gtreqless 0 .
$$

Equation (34) reveals that the sign of $\frac{d U}{d n}$ depends solely on the sign of $\left(n-f^{\prime}\right)$. Hence an increase of per capita debt increases (decreases) per capita utility if the economy is experiencing over-accumulation (under-accumulation) in the steady state equilibrium. Thus, debt should be issued (recovered) up to the point where golden rule growth is attained.

Population Growth and Welfare: The same indirect utility function can now be used to derive the welfare implications which originate from changes in the growth rate for population:

$$
U\left(c^{1}, c^{2}\right)=U\left(f(k)-k f^{\prime}(k)-(1+n) k-\left(1+f^{\prime}(k)\right) b,\left(1+f^{\prime}(k)\right)(1+n)(k+b)\right) .
$$

The first derivative with respect to the growth rate of population is:

$$
\begin{aligned}
\frac{d U}{d n} & =-U_{c^{1}}\left(\left[(k+b) f^{\prime \prime}+(1+n)\right] \frac{d k}{d n}+k\right) \\
& +U_{c^{2}}\left(\left[(1+n)\left(1+f^{\prime}\right)+f^{\prime \prime}(1+n)(b+k)\right] \frac{d k}{d n}+\left(1+f^{\prime}\right)(k+b)\right) .
\end{aligned}
$$

Using (22), we obtain:

$$
\frac{d U}{d n}=U_{c^{1}} b+U_{c^{1}} \frac{\left(n-f^{\prime}\right)(k+b)}{1+f^{\prime}} f^{\prime \prime} \frac{d k}{d n} \gtreqless 0 ; \quad \frac{d k}{d n}<0 .
$$

The first order derivative (36) contains two elements: the first element $U_{c^{1}} b>0$ (for $b>0)$ is the biological interest rate effect, which suggests that population should grow as fast as possible. The reason for the appearance of the biological interest argument is the following: each young individual buys government debt amounting to $(1+n) b$ and pays taxes $\left(f^{\prime}(k)-n\right) b$. Hence the young individual hands over a total amount of $\left(1+f^{\prime}(k)\right) b$ to the government. In the retirement period the government serves its obligations and pays $\left(1+f^{\prime}(k)\right)(1+n) b$.

Thus the individual receives the biological rate of interest $(1+n)$ on its total payments. This also reveals that the total amount of resources which is transferred into the retirement period, at the biological rate of interest, depends on the rate of interest $\left(1+f^{\prime}(k)\right)$ and hence, via the capital intensity, on the growth rate of population. 
The second element $U_{c^{1}} \frac{\left(n-f^{\prime}\right)(k+b)}{1+f^{\prime}} f^{\prime \prime} \frac{d k}{d n}$ describes the factor-price effects which originate from a change in the growth rate of population. An increase in $n$ leads to a fall in $k$, which increases the interest rate payed on capital and debt, and decreases wages.

In the special case $b=0,(36)$ degenerates into (15) where $\frac{d U}{d n}=0$ for $n=n^{*}$, and at $n^{*}$ the pair of factor-prices $w\left(k\left(n^{*}\right)\right), r\left(k\left(n^{*}\right)\right)$ ensure maximum (minimum) lifetime utility. The tradeoff is solely between wages and interest.

In the case $b \neq 0$ the situation differs fundamentally: as (36) indicates, the tradeoff is now between what we will call the aggregate factor-price effects and the biological interest rate. The growth rate which maximizes (minimizes) laissez faire utility in an economy with government debt will be referred to as $n^{* *}$. We can note that $n^{* *}$ is larger (for Case $1, b>0$ ) than the growth rate $\tilde{n}$ which causes a golden rule allocation, and it may or may not be larger than $n^{*}$. The conditions which have to be met to allow for a laissez faire optimum at $n^{* *}$ remain, compared to the case without debt, basically unaltered with $\frac{d r}{d n}>1$; the only additional condition is that the difference $\left(n-f^{\prime}(k(n))\right)$ must increase sufficiently to allow for an interior optimum at $n^{* *}$.

Proposition 2: In a laissez faire economy with constant per capita government debt the growth rate of population, which leads to a golden rule allocation, can never be optimal.

Using Case 1 with $b>0$ as the example, the foregoing discussion concerning the optimum growth rate of population in an economy with government debt can be summarized in Diagram 3: 


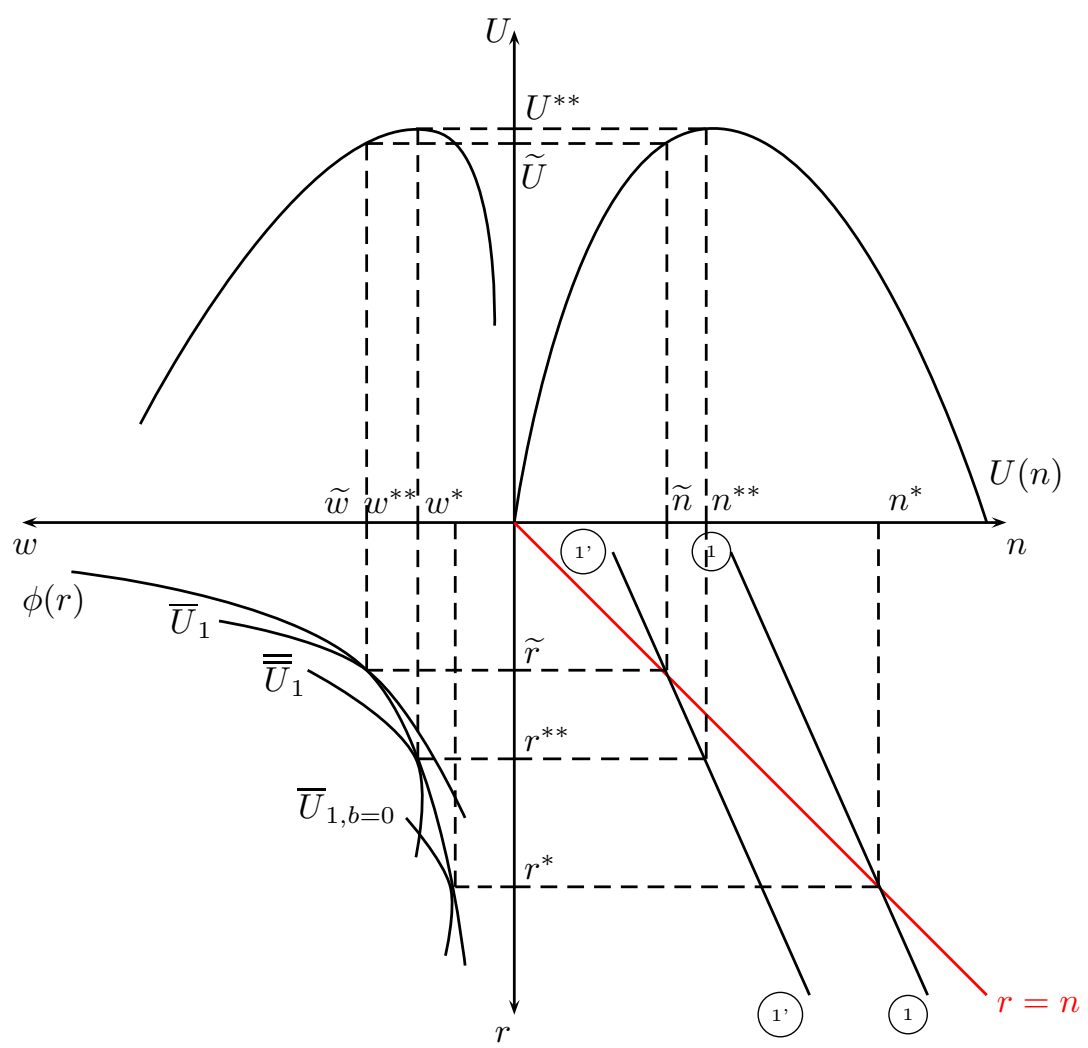

Diagram 3: The optimum growth rate for population in a laissez faire economy (Case 1, b > 0) with government debt.

Diagram 3 illustrates that the optimum growth rate for population $n^{* *}$ is larger than $\tilde{n}$. Compared to the case without debt the preference ordering in the $w, r$ quadrant is changed since the interest rate is not only determining the relative price of future consumption; it also determines the total amount of resources which go through the hands of the government and yield the biological interest rate. Thus the indifference curves with debt $\bar{U}_{1}$ and $\overline{\bar{U}}_{1}$ may intersect the indifference curve $\bar{U}_{1, b=0}$. At the optimum growth rate for population $n^{* *}$, which might be larger, smaller or equal to the optimal $n^{*}$ of Samuelson (1975a), we have $\left(n^{* *}-f^{\prime}\left(k\left(n^{* *}\right)\right)\right)<0$. Hence, according to (34), the government can always improve steady state utility through a reduction of per capita debt. The (social) optimum optimorum would once again be reached at $n^{*}$ with $b=0$ (the $U(n)$ curve for the planned economy is not included in Diagram 3). 


\section{Concluding Remarks}

In the first section we developed a general approach to the problem of optimal population in the Diamond (1965) model without government debt. This led to the conclusion that:

1. The qualitative necessary and sufficient conditions for the existence of an interior optimum growth rate for population in a planned and in a laissez-faire economy are identical. In both cases it is the convex factor-price frontier which can be interpreted as the social budget constraint. Hence we have shown that the findings of Michel and Pestieau (1993) for the planned economy remain also valid in the more interesting and realistic case of a laissez faire framework.

2. There always exists an interior optimum in an economy where low (high) growth rates for population lead to over-accumulation (under-accumulation). The general sufficient condition for an interior optimum in a laissez-faire as well as a planned economy is hence given by $\left.\frac{d r}{d n}\right|_{n=n^{*}}>1$. All cases where there exists an interior minimum, like the Cobb-Douglas case, are consistent with an economy, where rapid population growth leads to overaccumulation and where low or negative growth rates for population lead to under accumulation.

3. An increase in the growth rate for population increases (decreases) steady state welfare only if the economy is growing on an inefficient (efficient) steady state path.

In a second step we generalized the discussion by introducing government debt. In such a framework we find that:

1. Due to the substitution between debt and capital in the portfolios of the representative individuals, the Serendipity Theorem does not hold anymore. However, except for the case of permanent efficiency there still exists at least one growth rate for population $\tilde{n}$, which leads the laissez faire economy to (two-part) golden rule growth.

2. In a laissez faire economy with constant per capita debt, the growth rate for population $\tilde{n}$, which leads to a golden rule allocation can never be optimal since it only balances the wage-interest tradeoff. The optimum growth rate for population balances the tradeoff between factor-prices and the internal rate of return of 
the pension/debt scheme. Such an optimum growth rate leads the competitive economy to an allocation where the marginal productivity of capital exceeds the optimum growth rate for population.

\section{A Appendix}

The formal aspects to Diagram 1: The factor-price frontier is given by:

$$
w=\phi(r) ; \quad \frac{d w}{d r}=\phi^{\prime}(r)=-k ; \quad \frac{d^{2} w}{d r^{2}}=\phi^{\prime \prime}(r)=\frac{-1}{f^{\prime \prime}} .
$$

The indifference curve of the representative individual in the $w, r$ plane is:

$$
U=U(w, r) ;\left.\quad \frac{d w}{d r}\right|_{\mid d U=0}=\frac{-s(w, r)}{(1+r)} ; \quad{\frac{d^{2} w}{d r^{2}}}_{\mid d U=0}=\frac{s_{w} s(w, r)-s_{r}(1+r)+s(w, r)}{(1+r)^{2}} .
$$

Using the Serendipity Theorem we can show that the first order condition for a laissez faire/planned optimum at an interior $n^{*}$ is satisfied if $\phi^{\prime}(r)=\frac{d w}{d r} \mid d U=0$ at $n^{*}$ :

$$
-k^{*}+\frac{c^{2 *}}{\left(1+n^{*}\right)^{2}}=0 \Leftrightarrow-k^{*}=\frac{-s^{*}}{\left(1+f^{\prime}\left(k\left(n^{*}\right)\right)\right)} ; \quad f^{\prime}\left(k\left(n^{*}\right)\right)=n^{*} ; \quad c^{2 *}=\left(1+n^{*}\right) s^{*} .
$$

Q.E.D.

Now we will show that the sufficient condition $\frac{d^{2} w}{d r^{2}} \mid d U=0>\phi^{\prime \prime}(r)$ can be transformed into $f^{\prime \prime}(k) \frac{d k}{d n}>1$, which was our sufficient condition (compare with (16) and (17)) for a laissez faire optimum at $n^{*}$ :

$$
\frac{s_{w} s(w, r)-s_{r}(1+r)+s(w, r)}{(1+r)^{2}}>\frac{-1}{f^{\prime \prime}}
$$

at the stationary point we have $s=(1+n) k$ and $n=n^{*}=r$, and hence:

$$
\frac{s_{w}(1+n) k-s_{r}(1+n)+(1+n) k}{(1+n)}>\frac{-1}{f^{\prime \prime}}(1+n),
$$

this can be rearranged such that:

$$
-k<\frac{1}{f^{\prime \prime}}(1+n)+s_{w} k-s_{r}
$$

with $\frac{1}{f^{\prime \prime}}(1+n)+s_{w} k-s_{r}<0$ by virtue of the stability condition (12). Thus we obtain:

$$
\frac{-k}{\frac{1}{f^{\prime \prime}}(1+n)+s_{w} k-s_{r}}>1 \quad \Leftrightarrow \quad f^{\prime \prime}(k) \frac{d k}{d n}>1 .
$$

Q.E.D. 


\section{B Appendix}

Proof of Proposition 1: It flows directly from the Serendipity Theorem that the first order conditions for the existence of an interior $n^{*}$ in the planned economy and the laissez faire economy both identify the same stationary point; for $n=n^{*}=r^{*}$, conditions (6) and (15) are both satisfied.

We will now prove that the same is true for the sufficient conditions. Thus we have to show that the sufficient condition for an optimal interior $n^{*}$ in the planned economy is only satisfied if $\frac{-k}{\frac{1}{f^{\prime \prime}}(1+n)+s_{w} k-s_{r}}>1$ at the stationary point.

The second order derivative of the indirect utility function (5) for the planned economy was given by:

$$
{\frac{d^{2} U}{d n^{2}}}_{\mid n=n^{*}}=U_{c^{1}}\left(-\frac{d k_{n}}{d n}+\frac{(1+n)^{2} \frac{d c_{n}^{2}}{d n}-2(1+n) c_{n}^{2}}{(1+n)^{4}}\right) \gtreqless 0 .
$$

The sign of this second order derivative hinges on two distinct elements: the first element $\frac{d k_{n}}{d n}$ is the aspect of optimal capital accumulation. The second element $\frac{(1+n)^{2} \frac{d c_{n}^{2}}{d n}-2(1+n) c_{n}^{2}}{(1+n)^{4}}$ is concerned with the optimal consumption pattern.

From the first order condition for the optimal capital accumulation pattern we have:

$$
r_{n}=f^{\prime}\left(k_{n}\right)=n, \quad \frac{d k_{n}}{d n}=\frac{1}{f^{\prime \prime}\left(k_{n}\right)} .
$$

For the second element, which is concerned with the optimal consumption pattern, we find that in a planned economy we have:

$$
\begin{aligned}
& \frac{U_{c^{1}}\left(c_{n}^{1}, c_{n}^{2}\right)}{U_{c^{2}}\left(c_{n}^{1}, c_{n}^{2}\right)}=1+n, \\
& w_{n}=f\left(k_{n}\right)-n k_{n}=c_{n}^{1}+\frac{c_{n}^{2}}{(1+n)^{2}} .
\end{aligned}
$$

These two equations clearly define an optimal consumption pattern $c_{n}^{1}$ and $c_{n}^{2}$, where $c_{n}^{2}=(1+n) s\left(w_{n}, r_{n}\right)$; once the individual faces the biological rate of interest it will voluntarily (for all given real wages $w_{n}$ ) choose the optimal (biological) consumption pattern (Samuelson (1958) and Cass and Yaari (1966)). Hence:

$$
\frac{d c_{n}^{2}}{d n}=\frac{d\left[(1+n) s\left(w_{n}, r_{n}\right)\right]}{d n}=s\left(w_{n}, r_{n}\right)+\left(s_{w} \frac{d w_{n}}{d n}+s_{r} \frac{d r_{n}}{d n}\right)(1+n),
$$

with:

$$
\frac{d r_{n}}{d n}=1 ; \quad \frac{d w_{n}}{d n}=f^{\prime}\left(k_{n}\right) \frac{d k_{n}}{d n}-k_{n}-n \frac{d k_{n}}{d n}=-k_{n} .
$$


We can now substitute the expressions in (38) and (39) into (37) to evaluate the sign of $\frac{d^{2} U}{d n^{2}}$ at the stationary point, where we have $c_{n}^{2 *}=\left(1+n^{*}\right) s\left(w^{*}, r^{*}\right)=\left(1+n^{*}\right)^{2} k^{*}$ :

$$
{\frac{d^{2} U}{d n^{2}}}_{\mid n=n^{*}}=U_{c^{1}}\left(-\frac{1}{f^{\prime \prime}\left(k^{*}\right)}+\frac{\left(1+n^{*}\right)^{3} k^{*}+\left(-s_{w} k^{*}+s_{r}\right)\left(1+n^{*}\right)^{3}}{\left(1+n^{*}\right)^{4}}-\frac{2\left(1+n^{*}\right)^{3} k^{*}}{\left(1+n^{*}\right)^{4}}\right) .
$$

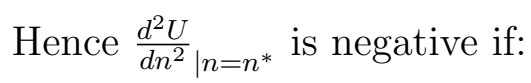

$$
-k^{*}<\left(1+n^{*}\right) \frac{1}{f^{\prime \prime}\left(k^{*}\right)}+s_{w} k^{*}-s_{r}
$$

According to the stability condition (12) we have $\left(1+n^{*}\right) \frac{1}{f^{\prime \prime}\left(k^{*}\right)}+s_{w} k^{*}-s_{r}<0$ and we find that $\left.\frac{d^{2} U}{d n^{2}}\right|_{n=n^{*}}<0$ if and only if:

$$
\frac{-k^{*}}{\left(1+n^{*}\right) \frac{1}{f^{\prime \prime}\left(k^{*}\right)}+s_{w} k^{*}-s_{r}}>1
$$

This sufficient condition for a social optimum (41) is identical with the sufficient condition (17) for a laissez faire optimum at $n^{*}$. Q.E.D.

\section{References}

Cass, D. and Yaari, M. E. (1966). A re-examination of the pure consumption loans model. The Journal of Political Economy, (Vol. 74, No. 4):353-367.

De La Croix, D. and Michel, P. (2002). A Theory of Economic Growth. Cambridge: Cambridge Univ. Press.

Deardorff, A. V. (1976). The optimum growth rate for population: Comment. International Economic Review, (Vol. 17, No. 2 (Jun., 1976)):510-515.

Diamond, P. A. (1965). National debt in a neoclassical growth model. The American Economic Review, (Vol. 55, No. 5, Part 1 (Dec., 1965)):1126-1150.

Jaeger, K. (1989). The serendipity theorem reconsidered: The three-generations case without inheritance. In Economic theory of optimal population, pages 75-87. ed. Klaus F. Zimmermann, Springer.

Marquetti, A. A. (2004). Extended penn world tables 2.1. http://homepage. newschool . edu/ foleyd/epwt[12.10.2006].

Michel and Pestieau (1993). Population growth and optimality: When does serendipity hold. Journal of Population Economics, (Vol. 6, No. 4):353-362. 
Persson and Tabellini (2000). Political Economics. MIT Press.

Phelps, E. (1967). The golden rule of procreation. In Golden Rules of Economic Growth, pages 176-183. ed. Edmund Phelps, North Holland Publishing Company, Amsterdam.

Phelps, E. (1968). Population increase. The Canadian Journal of Economics, (Vol. 1, No.3):497-518.

Samuelson, P. A. (1958). An exact consumption-loan model of interest with or without the social contrivance of money. The Journal of Political Economy, (Vol. 66, No. $6): 467-482$.

Samuelson, P. A. (1975a). The optimum growth rate for population. International Economic Review, (Vol. 16, No. 3):531-538.

Samuelson, P. A. (1975b). Optimum social security in a life-cycle growth model. International Economic Review, (Vol. 16, No. 3):539-544.

Samuelson, P. A. (1976). The optimum growth rate for population: Agreement and evaluations. International Economic Review, (Vol. 17, No. 2):516-525. 


\section{Discussion Paper Series}

Mannheim Research Institute for the Economics of Aging Universität Mannheim

To order copies, please direct your request to the author of the title in question.

\begin{tabular}{|c|c|c|c|}
\hline Nr. & Autoren & Titel & Jahr \\
\hline $135-07$ & Axel Börsch-Supan & Work Disability, Health, and Incentive Effects & 07 \\
\hline $136-07$ & $\begin{array}{l}\text { Axel Börsch-Supan, } \\
\text { Anette Reil-Held, } \\
\text { Daniel Schunk }\end{array}$ & $\begin{array}{l}\text { The savings behaviour of German households: } \\
\text { First Experiences with state promoted private } \\
\text { pensions }\end{array}$ & 07 \\
\hline $137-07$ & $\begin{array}{l}\text { Hendrik Jürges, } \\
\text { Mauricio Avendano, } \\
\text { Johan Mackenbach }\end{array}$ & $\begin{array}{l}\text { How comparable are different measures of self- } \\
\text { rated health? Evidence from five European } \\
\text { countries }\end{array}$ & 07 \\
\hline $138-07$ & $\begin{array}{l}\text { Hendrik Jürges, } \\
\text { Kerstion Schneider }\end{array}$ & $\begin{array}{l}\text { What can go wrong will go wrong: Birthday } \\
\text { effects and early tracking in the German school } \\
\text { system }\end{array}$ & 07 \\
\hline $139-07$ & Hendrik Jürges & $\begin{array}{l}\text { Does ill health affect savings intentions? } \\
\text { Evidence from SHARE }\end{array}$ & 07 \\
\hline $140-07$ & Hendrik Jürges & $\begin{array}{l}\text { Health inequalities by education, income, and } \\
\text { wealth: a comparison of } 11 \text { European countries } \\
\text { and the US }\end{array}$ & 07 \\
\hline $141-07$ & Hendrik Jürges & $\begin{array}{l}\text { Healthy minds in healthy bodies. An } \\
\text { international comparison of education-related } \\
\text { inequality in physical health among older adults }\end{array}$ & 07 \\
\hline $142-07$ & $\begin{array}{l}\text { Karsten Hank, } \\
\text { Stephanie Stuck }\end{array}$ & $\begin{array}{l}\text { Volunteer Work, Informal Help, and Care among } \\
\text { the 50+ in Europe: Further Evidence for 'Linked' } \\
\text { Productive Activities at Older Ages }\end{array}$ & 07 \\
\hline $143-07$ & Jürgen Maurer & $\begin{array}{l}\text { Assessing Horizontal Equity in Medication } \\
\text { Treatment Among Elderly Mexicans: Which } \\
\text { Socioeconomic Determinants Matter Most? }\end{array}$ & 07 \\
\hline $144-07$ & Jürgen Maurer & $\begin{array}{l}\text { Socioeconomic and Health Determinants of } \\
\text { Health Care Utilization Among Elderly } \\
\text { Europeans: A Semiparametric Assessment of } \\
\text { Equity, Intensity and Responsiveness for Ten } \\
\text { European Countries }\end{array}$ & 07 \\
\hline $145-07$ & Jürgen Maurer & $\begin{array}{l}\text { Modelling socioeconomic and health } \\
\text { determinants of health care use: A } \\
\text { semiparametric approach }\end{array}$ & 07 \\
\hline $146-07$ & $\begin{array}{l}\text { Jérome Adda, James } \\
\text { Banks, Hans-Martin } \\
\text { von Gaudecker }\end{array}$ & $\begin{array}{l}\text { The Impact of Income Shocks on Health: } \\
\text { Evidence from Cohort Data }\end{array}$ & 07 \\
\hline $147-07$ & $\begin{array}{l}\text { Klaus Jäger, } \\
\text { Wolfgang Kuhle }\end{array}$ & $\begin{array}{l}\text { The Optimum Growth Rate for Population } \\
\text { Reconsidered }\end{array}$ & 07 \\
\hline
\end{tabular}

